Jurnal Cendekia Akuntansi

Kediri, Desember 2021

\title{
ANALISIS PENENTUAN HARGA JUAL JASA MAKE UP DAN HAIRDO MENGGUNAKAN MODEL COST PLUS PRICING (Studi Kasus Pada Salon Ima Skincare dan Make Up Desa Kenongo Kecamatan Wlingi Kabupaten Blitar)
}

\author{
Almira Fausta Zafirah \\ Rumanintya Lisaria Putri \\ Universitas Islam Balitar \\ E-mail: almirafz7@gmail.com
}

\begin{abstract}
Abstrak
Salon Ima Skincare dan Make Up Desa Kenongo Kecamatan Wlingi Kabupaten Blitar merupakan salah satu penyedia jasa make up \& hairdo yang merangkap sebagai MUA (Make Up Artist) di Kabupaten Blitar. Salon ini memiliki beberapa layanan jasa make up yang telah disusun dalam bentuk paket maupun non paket atau lepasan. Penyusunan paket maupun non paket jasa tersebut tidak lepas dari adanya penentuan harga jual. Penentuan harga jual yang ditetapkan oleh Salon Ima masih menggunakan metode harga jual yang ditetapkan oleh produsen atau menggunakan metode harga jual relatif, yaitu harga jual yang mengikuti harga pasaran yang telah ditetapkan oleh usaha yang sejenis. Mengacu pada hal itu perlu adanya penggunaan metode cost plus pricing yaitu metode dengan nilai biaya tertentu ditambah dengan kenaikan (mark up) yang ditentukan supaya pelaku usaha mendapatkan keuntungan sesuai dengan yang diinginkan. Tujuan penelitian ini adalah untuk mengetahui bagaimana perusahaan jasa menentukan harga jual make up dan hairdo dengan menggunakan metode cost plus pricing pada Salon Ima Skincare dan Make Up. Metode penelitian yang digunakan berupa penelitian kualitatif dengan pendekatan studi kasus. Data-data yang digunakan merupakan data primer yang dikumpulkan melalui observasi, wawancara, dokumentasi dan studi literatur. Hasil penelitian ini menunjukkan harga jual yang ditetapkan masih mengikuti harga pasaran yang ada. Oleh karena itu, manajemen perusahaan sebaiknya menggunakan metode cost plus pricing dalam mengidentifikasi biaya dan menghitung harga jualnya sehingga harga jual yang dicapai dapat bersaing dengan para pesaing yang memiliki usaha sejenis.
\end{abstract}

Kata Kunci: Harga Jual; Make Up \& Hairdo; Cost Plus Pricing.

\section{Abstract}

Ima Skincare and Make Up Salon Kenongo Village, Wlingi District, Blitar Regency is one of the make up \& hairdo service providers who doubles as MUA (Make Up Artist) in Blitar Regency. This salon has several make up services that have been arranged in the form of packages or non-packages or loose. The 
preparation of packages and non-service packages cannot be separated from the determination of the selling price. Determination of the selling price set by Salon Ima still uses the selling price method set by the manufacturer or using the relative selling price method, namely the selling price that follows the market price set by similar businesses. Referring to this, it is necessary to use the cost plus pricing method, which is a method with a certain cost value plus a specified mark-up so that business actors get the desired profit. The purpose of this study is to find out how service companies determine the selling price of make up and hairdo using the cost plus pricing method at the Ima Skincare and Make Up Salon. The research method used is a qualitative research with a case study approach. The data used are primary data collected through observation, interviews, documentation and literature study. The results of this study indicate that the selling price set still follows the existing market price. Therefore, company management should use the cost plus pricing method in identifying costs and calculating the selling price so that the selling price achieved can compete with competitors who have similar businesses.

Keywords: Selling Price; Make Up \& Hairdo; Cost Plus Pricing.

\section{PENDAHULUAN}

Seiring berkembangnya perekonomian di Indonesia yang di iringi dengan kemajuan ilmu pengetahuan dan teknologi, banyak sekali persaingan diantara para pengusaha jasa. Persaingan yang semakin tajam inilah yang mendorong para pengusaha untuk memikirkan bagaimana memberikan pelayanan yang baik dan jasa yang berkualitas, sehingga konsumen akan lebih selektif memilih jasa yang akan dibelinya.

Dengan semakin berkembangnya zaman seperti sekarang ini, di Kabupaten Blitar juga sudah banyak sekali pengusaha jasa yang bergerak dalam bidang kecantikan seperti MUA (Make Up Artist). MUA banyak sekali digunakan untuk golongan masyarakat menengah ke atas pada khususnya dalam menghadiri berbagai macam acara serta momen tertentu. Berbagai acara yang seringkali melibatkan MUA misalnya wedding service, bridesmaid, among tamu, bahkan hanya sekadar menghadiri undangan yang sifatnya non resmi maupun resmi juga melibatkan jasa dari MUA. Hal ini tentu dapat memberikan jalan atau peluang bagi para MUA dalam menerima banyak tawaran kerja sama dari customer.

Di dukung dengan sosial media yang semakin berkembang seperti sosial media Instagram yang beberapa tahun terakhir ini semakin familiar di kehidupan masyarakat luas membuat MUA semakin memiliki peluang besar. Semua para pemilik jasa MUA hanya cukup dengan mengunggah hasil karyanya, sehingga dapat memudahkan konsumen untuk melihat semua hasil karya dari berbagai pemiliki jasa MUA serta dapat memancing minat para customer yang membutuhkan jasanya.

Semakin banyaknya pengusaha jasa dalam bidang MUA yang bermunculan di Indonesia, termasuk di Jawa Timur menyebabkan terjadinya suatu persaingan yang ketat diantara usaha-usaha yang umumnya menawarkan berbagai macam jasa serupa antara satu usaha dengan usaha lainnya. Munculnya jasa yang serupa seperti jasa MUA ini membuat banyak pengusaha jasa mengalami fluktuasi 
harga atau perang harga antar sesama pengusaha. Hal ini menjadi tantangan bagi pelaku usaha agar tetap dapat berkembang dan terus menjalankan usahanya dalam menghadapi persaingan.

Agar dapat menghadapi persaingan, pengusaha jasa MUA harus mempunyai strategi yang tepat agar dapat tetap bersaing dengan usaha lainnya. Salah satu strateginya adalah membuat suatu kebijakan dalam menentukan harga jual. Menurut Alma (2014:171) penentuan harga adalah keputusan mengenai harga-harga yang akan diikuti dalam jangka waktu tertentu. Harga jual merupakan nilai tukar suatu produk atau jasa, yaitu jumlah uang yang pembeli sanggup membayar kepada penjual untuk suatu produk atau jasa tertentu (Sriyadi, 2010:178). Penentuan harga jual atas jasa yang diproduksi haruslah tepat tidak didasarkan pada perkiraan saja, tetapi dengan melakukan perhitungan yang akurat dan teliti karena apabila harga jual yang ditetapkan terlalu tinggi maka akan membuat konsumen mencari alternatif lain atau bahkan membeli jasa di tempat lain dengan harga yang lebih murah dan berkualitas sebab usaha kurang bersaing di pasaran, dan sebaliknya apabila harga jual yang ditetapkan pengusaha jasa terlalu rendah maka biaya yang dikeluarkan tidak tertutup dan menyebabkan usaha mengalami kerugian. Maka, harga jual diharapkan dapat menutup semua biaya yang telah dikeluarkan oleh suatu perusahaan dan harga jual juga harus dapat menghasilkan laba yang sesuai dengan keinginan perusahaan.

Faktor biaya merupakan faktor utama dalam menentukan harga jual, karena biaya menggambarkan batas minimum yang harus dipenuhi oleh setiap pelaku usaha agar usahanya tidak mengalami kerugian. Biaya merupakan kas yang telah dikorbankan untuk digunakan dalam membeli barang maupun jasa yang diharapkan dapat memberikan manfaat bagi pelaku usaha dimasa sekarang maupun untuk periode mendatang (Krismiaji dan Aryani, 2011:17). Salah satu contoh penerapan dari faktor biaya ini dijalankan oleh para pengusaha jasa terutama jasa MUA yang mana pelaku usaha dituntut harus mengelola biaya sebaik mungkin dalam upaya untuk menghadapi persaingan yang sangat ketat. Semakin baik kemampuan mengelola biaya, maka semakin baik pula kualitas dan harga jual jasa yang ditawarkan kepada konsumen.

Umumnya, harga jual yang ditetapkan suatu usaha jasa dapat berbeda dengan harga jual usaha yang sejenis, hal ini disebabkan oleh kondisi dari masingmasing pengusaha yang berbeda. Karena hal itu, keputusan penentuan harga jual dalam suatu usaha bisa diperkirakan sesuai perhitungan laba yang ingin dicapai bagi masing-masing pelaku usaha. Maka dari itu, untuk dapat menentukan harga jual yang sesuai perlu dihitung dengan sebenar-benarnya, diperlukan suatu evaluasi yang berkesinambungan terhadap harga jual yang ditetapkan, dan disesuaikan dengan kondisi yang sedang di hadapi oleh pelaku usaha sehingga dapat dikendalikan dan diketahui apakah harga jual tersebut masih sesuai dengan kondisi yang ada.

Namun, realita di lapangan berdasarkan proses observasi dan wawancara bersama pemilik usaha Salon Ima Skincare dan Make Up yaitu Ibu Khusnul Khotimah, penentuan harga jual jasa di Salon Ima Skincare dan Make Up yang ada di Desa Kenongo Kecamatan Wlingi Kabupaten Blitar memiliki masalah dalam menentukan harga jualnya. Berdasarkan harga jual yang ditetapkan selama 
ini pemilik usaha Salon Ima Skincare dan Make Up belum menargetkan atau mematok keuntungan yang diinginkannya dan belum memperhitungkan serta mengelompokkan komponen-komponen biaya yang membentuk harga jual yang telah dikeluarkan secara maksimal dan menyeluruh. Selama usaha ini beroperasi pemilik hanya menetapkan harga jual berdasarkan harga pasaran dan hanya memperhitungkan komponen biaya bahan baku, biaya tenaga kerja langsung, biaya lain-lain, dan biaya listrik sebagai biaya produksinya. Jadi, selama ini sebenarnya usaha dari Salon Ima Skincare dan Make Up tidak pernah melakukan perhitungan harga pokok secara terperinci. Apabila hal ini terus berlangsung tidak menutup kemungkinan laba yang di peroleh tidak akan sesuai dengan apa yang di harapkan, karna sejatinya tujuan dari suatu usaha yaitu untuk memperoleh laba yang optimal. Hal ini tentu sudah biasa karena dengan laba yang di peroleh secara optimal, maka pelaku usaha dapat mempertahankan hidup suatu usaha serta dapat memperluas usahanya.

Pernyataan di atas didukung dengan penelitian dari Ari Putri Rahmadhani dan Ari Kamayanti yang telah melakukan penelitian terlebih dahulu dengan judul "Etika Penentuan Harga Pada Perusahaan Jasa (Studi Kasus Pada Salon Kecantikan Di Kabupaten Ponorogo Jawa Timur)." Penelitian ini dilakukan pada tahun 2016 yang mana menghasilkan sebuah kesimpulan berkenaan dengan harga jual jasa sebagai fokus bahasan penelitian saat ini di mana Salon Kecantikan yang ada di Ponorogo dalam menentukan harga jual jasa yang dikeluarkan masih menyesuaikan dengan harga pasar di Kabupaten Ponorogo atau setara dengan harga jual salon kecantikan senior di Kabupaten Ponorogo.

Dari pernyataan di atas, diperlukan penggunaan metode penentuan harga jual agar pelaku usaha dapat menghasilkan laba sesuai dengan yang diinginkan. Ada berbagai macam metode yang bisa digunakan dalam menentukan harga jual. Salah satu metode dalam menentukan harga jual yang dapat digunakan pelaku usaha jasa yaitu metode cost plus pricing. Menurut Krismiaji dan Aryani (2011:326), cost plus pricing adalah menambahkan angka perkiraan laba (mark up) berupa persentase tertentu dari harga pokok produk. Jadi, metode cost plus pricing adalah jenis metode untuk menentukan harga jual di mana penentuan harga ini dilakukan dengan menambahkan laba atau keuntungan yang diharapkan atas biaya produksi dari suatu usaha.

Berdasarkan uraian di atas, maka peneliti tertarik untuk melakukan penelitian dengan judul "Analisis Penentuan Harga Jual Jasa Make Up dan Hairdo Menggunakan Model Cost Plus Pricing (Studi Kasus Pada Salon Ima Skincare dan Make Up Desa Kenongo Kecamatan Wlingi Kabupaten Blitar)"

\section{METODE PENELITIAN}

Penelitian ini menggunakan jenis penelitian kualitatif. Penelitian kualitatif merupakan sebuah metode penelitian yang memanfaatkan data kualitatif yang dijabarkan secara deskriptif. Data-data yang diperoleh dari informan dihimpun secara lisan yang berupa kata-kata dan gambar, bukan berupa angka. Penelitian ini bersifat penelitian lapangan di mana peneliti mengambil data langsung ke lapangan dengan melakukan wawancara terhadap narasumber. Melalui penelitian kualitatif ini, peneliti bermaksud untuk memperoleh gambaran yang mendalam 
tentang penentuan harga jual jasa make up dan hairdo dengan menggunakan model cost plus pricing pada Salon Ima Skincare dan Make Up di Desa Kenongo, Kecamatan Wlingi, Kabupaten Blitar, Jawa Timur.

Subjek pada penelitian ini adalah pemilik usaha dari Salon Ima Skincare dan Make Up yaitu Ibu Khusnul Khotimah. Sedangkan, untuk objek dari penelitian ini adalah penentuan harga jual jasa make up dan hairdo dengan menggunakan model cost plus pricing yang ada di Salon Ima Skincare dan Make Up Kecamatan Wlingi Kabupaten Blitar.

Sumber data yang digunakan dalam penelitian ini berasal dari data primer dan data sekunder. Data primer yang didapatkan peneliti, meliputi data harga jual jasa paket akad di Salon Ima Skincare dan Make Up, serta data harga jual jasa bundling package wedding di Salon Ima Skincare dan Make Up. Sedangkan, untuk data sekunder diperoleh secara tidak langsung dari sumber informan. Data sekunder yang didapatkan dari penelitian ini bisa berupa jurnal, artikel, laporan skripsi, dan sebagainya yang relevan dengan penelitian saat ini yaitu serupa dalam membahas harga jual jasa make up dan hairdo.

Teknik pengumpulan data yang dilakukan oleh peneliti untuk melakukan analisis pada penentuan harga jual jasa make up dan hairdo dengan menggunakan model cost plus pricing di Salon Ima Skincare dan Make Up Kabupaten Blitar meliputi observasi, wawancara, studi pustaka, dan dokumentasi.

\section{PEMBAHASAN}

\section{Penentuan Harga Jual Paket Akad di Salon Ima Skincare \& Make Up}

Penentuan harga jual yang tepat dalam suatu usaha sangatlah penting. Sebab tanpa ditunjang adanya metode penentuan harga jual yang tepat, maka tidak mungkin suatu usaha dapat memperoleh laba yang diinginkan. Harga jual ditentukan dengan menambah biaya yang dikeluarkan dan laba yang diinginkan. Perolehan laba yang maksimal merupakan target dari setiap usaha. Hal ini sesuai dengan kutipan wawancara dengan Ibu Khusnul Khotimah selaku pemilik usaha Salon Ima Skincare \& Make Up yang disajikan sebagai berikut :

"Di sini ada berbagai tingkatan harga jual dari jasa akad, mbak. List harga dari jasa akad yang ada di sini terbagi menjadi 4 (empat) macam, yaitu jasa make up akad, paket akad 1, paket akad 2, dan paket akad 3. Harga jual jasa dari masing-masing jasa tersebut bervariasi mulai dari Rp. 1.500.000,, Rp. 2.200.000,-, Rp. 3.500.000,-, dan Rp. 5.500.000. Untuk paket make up akad terdiri dari make up dan 1x hijab do. Apabila hijab do ingin diganti dengan modern hair do, maka harga yang ditawarkan sebesar Rp. 400.000,-. Selain itu, ada melati segar, softlens, fake nail (tidak custom), dan premium eyelash. Untuk paket akad 1 meliputi make up dan 1x hijab do. Apabila hijab do ingin diganti dengan modern hair do, maka harga yang ditawarkan sebesar Rp. 400.000,-. Selain itu, ada sepasang sepatu, melati segar, serta softlens, dan fake nail (tidak custom). Untuk paket akad 2 memiliki 2 opsi. Opsi pertama, yaitu make up dan 1x hijab do, sepasang baju, melati segar, softlens dan fake nail, dekorasi 3,5 meter, hand bouquet, kursi pengantin dan meja akad. Sedangkan, opsi kedua yaitu make up dan hijab do, sepasang baju, melati segar, softlens dan fake nail, 
photographer, album magnetik, all file in disc, dan unlimited shoot. Terakhir, paket akad 3 meliputi make up dan hijab do, sepasang baju, melati segar, softlens dan fake nail, dekorasi 3,5 meter, hand bouquet, kursi pengantin, meja akad lesehan, photographer, album magazine 20 pages, all file in disc, dan video sinematik."

Untuk lebih lanjut, Ibu Khusnul juga menambahkan berbagai ketentuan yang berkaitan dengan paket akad, sebagai berikut.

"Untuk akad yang dilakukan dengan konsep tradisional Solo Putri beserta hair do ditarik harga sebesar Rp. 900.000,-, sedangkan untuk harga jual jasa akad dengan konsep Sunda Siger beserta hijab ditarik harga sebesar Rp. 750.000,-. Di Salon Ima ini memiliki ketentuan dan biaya tambahan untuk fasilitas yang diinginkan di luar fasilitas paket dalam penggunaan paket akad berupa disediakannya jasa temu dan sewa alat sebesar Rp. 350.000,-, dan jasa henna sebesar Rp. 300.000,-. Untuk ketentuan administrasi dari Salon Ima sendiri yaitu DP minimal Rp.500.000,- untuk lock tanggal akad, paket akad 1,2, dan 3 free ongkos kirim transport dan konsumen hanya dapat melakukan $2 \mathrm{x}$ perubahan sejak mengisi form wedding."

Dari pernyataan di atas, maka dapat disimpulkan bahwa harga jual paket akad di Salon Ima Skincare \& Make Up Desa Kenongo Kecamatan Wlingi Kabupaten Blitar memiliki harga jual yang berbeda untuk setiap paketnya. Berikut ini daftar paket akad yang ada di Salon Ima Skincare \& Make Up.

Tabel 1 Data Harga Jual Jasa Make Up Akad

\begin{tabular}{|l|c|}
\hline Jenis Biaya & Total Biaya (Rp) \\
\hline $\begin{array}{l}\text { Make up \& 1x hijab do } \\
\text { (Modern hair do + Rp. 400.000) }\end{array}$ & \\
\cline { 1 - 1 } Melati segar & \\
\cline { 1 - 1 } Softlens & \\
\cline { 1 - 1 } Fake nail (no custom) 1.500 .000 \\
\cline { 1 - 1 } Premium eyelash & \\
\hline
\end{tabular}

Sumber : Data Diolah, 2021.

Berdasarkan Tabel 1 di atas menunjukkan data harga jual jasa make up akad yang ada di Salon Ima Skincare \& Make Up. Harga jual jasa make up akad yang ada di sana dipatok dengan harga sebesar Rp. 1.500.000,-. Include yang didapatkan customer dari harga tersebut berupa make up dan 1x hijab do, melati segar, softlens, fake nail dan premium eyelash.

Tabel 2 Data Harga Jual Paket Akad 1

\begin{tabular}{|l|c|}
\hline Jenis Biaya & Total Biaya (Rp) \\
\hline $\begin{array}{l}\text { Make up \& 1x hijab do } \\
\text { (Modern hair do + Rp. 400.000) }\end{array}$ & \\
\cline { 1 - 1 } Melati segar & \\
\cline { 1 - 1 } Softlens & \\
\cline { 1 - 1 } Fake nail (no custom) 2.200 .000 \\
\cline { 1 - 1 } Premium eyelash & \\
\hline
\end{tabular}


Sumber : Data Diolah, 2021.

Berdasarkan Tabel 2 di atas menunjukkan data harga jual paket akad 1 yang ada di Salon Ima Skincare \& Make Up. Harga jual paket akad 1 yang ada di sana dipatok dengan harga sebesar Rp. 2.200.000,-. Include yang didapatkan customer dari harga tersebut berupa make up dan 1x hijab do, sepasang baju, melati segar, softlens, dan fake nail.

Tabel 3 Data Harga Jual Paket Akad 2

\begin{tabular}{|c|c|}
\hline Jenis Biaya & Total Biaya (Rp) \\
\hline Opsi 1 & \\
\hline Make up \& 1x hijab do & \multirow{8}{*}{ Rp. 3.500 .000} \\
\hline Sepasang baju & \\
\hline Melati segar & \\
\hline Softlens \& fake nail & \\
\hline Dekorasi 3,5 meter & \\
\hline Hand bouquet & \\
\hline Kursi pengantin & \\
\hline Meja akad lesehan & \\
\hline
\end{tabular}

Sumber : Data Diolah, 2021.

Berdasarkan Tabel 3 di atas menunjukkan data harga jual paket akad 2 opsi 1 yang ada di Salon Ima Skincare \& Make Up. Harga jual paket akad 2 opsi 1 yang ada di sana dipatok dengan harga sebesar Rp. 3.500.000,-. Include yang didapatkan customer dari harga tersebut berupa make up dan $1 \mathrm{x}$ hijab do, sepasang baju, melati segar, softlens \& fake nail, dekorasi 3,5 meter, hand bouquet, kursi pengantin, dan meja akad lesehan.

Tabel 4 Data Harga Jual Paket Akad 2

\begin{tabular}{|l|c|}
\hline \multicolumn{1}{|c|}{ Jenis Biaya } & \multicolumn{1}{|c|}{ Total Biaya (Rp) } \\
\hline Opsi2 & \\
\hline Make up \& 1x hijab do & \\
\hline Sepasang baju & \\
\hline Melati segar & \multirow{2}{*}{ Rp. 3.500 .000} \\
\cline { 1 - 1 } Softlens \& fake nail & \\
\hline Album magnetik & \\
\hline All file in disc & \\
\hline Unlimited shoot & \\
\hline Supher &
\end{tabular}

Sumber : Data Diolah, 2021.

Berdasarkan Tabel 4 di atas menunjukkan data harga jual paket akad 2 opsi 2 yang ada di Salon Ima Skincare \& Make Up. Harga jual paket akad 2 opsi 2 yang ada di sana dipatok dengan harga sebesar Rp. 3.500.000,-. Include yang didapatkan customer dari harga tersebut berupa make up dan 1x hijab do, sepasang baju, melati segar, softlens \& fake nail, photographer, album magnetik, all file in disc, dan unlimited shoot.

Tabel 5 Data Harga Jual Paket Akad 3

\begin{tabular}{|l|c|}
\hline Jenis Biaya & Total Biaya (Rp) \\
\hline Make up \& 1x hijab do & Rp. 5.500.000 \\
\hline
\end{tabular}




\begin{tabular}{|c|}
\hline Sepasang baju \\
\hline Melati segar \\
\hline Softlens \& fake nail \\
\hline Dekorasi 3,5 meter \\
\hline Hand bouquet \\
\hline Kursi pengantin \\
\hline Meja akad lesehan \\
\hline Photographer \\
\hline Album magazine 20 pages \\
\hline All file in disc \\
\hline Video sinematik \\
\hline
\end{tabular}

Sumber : Data Diolah, 2021.

Berdasarkan Tabel 5 di atas menunjukkan data harga jual paket akad 3 yang ada di Salon Ima Skincare \& Make Up. Harga jual paket akad 3 yang ada di sana dipatok dengan harga sebesar Rp. 5.500.000,-. Include yang didapatkan customer dari harga tersebut berupa make up dan 1x hijab do, sepasang baju, melati segar, softlens \& fake nail, dekorasi 3,5 meter, hand bouquet, kursi pengantin, dan meja akad lesehan, photographer, album magazine 20 pages, all file in disc, dan video sinematik.

\section{Penentuan Harga Jual Bundling Package Wedding di Salon Ima Skincare \& Make Up}

Penentuan harga jual yang tepat dari jasa wedding sangat penting dipahami dalam suatu usaha. Dengan memahami harga jual dari jasa wedding, dapat memudahkan pemilik usaha dalam memperoleh laba yang diinginkan. Harga jual ditentukan dengan menambah biaya yang dikeluarkan dan laba yang diinginkan. Perolehan laba yang maksimal merupakan target dari setiap usaha. Hal ini sesuai dengan kutipan wawancara dengan Ibu Khusnul Khotimah selaku pemilik usaha Salon Ima Skincare \& Make Up yang disajikan sebagai berikut :

"Harga jual jasa wedding di Salon Ima memberikan terobosan berupa bundling package wedding. Bundling package wedding dengan harga sebesar Rp. 18.000.000 memiliki 2 opsi include yang diberikan. Opsi pertama dari paket wedding senilai Rp. 18.000.000 ini meliputi paket make up, dokumentasi, dan dekorasi. Paket make up ini meliputi make up with retouch, 3 pasang baju pengantin, melati segar, henna dan fake nail, softlens, eyelash premium, aksesoris adat (Sunda Siger atau Solo Putri), make up sepasang orang tua dan besan serta kostum, make up pembawa kembar mayang beserta kostum, alat temu atau pemandu temu, bunga setaman, dan MC jawa. Untuk dokumentasi meliputi unlimited shoot, album magazine 20 pages, teaser 1 minutes, cinematic 3 minutes, 2 photographer, 1 videographer, 1 assisten, soft file back up, serta flashdisc, dan untuk dekorasi meliputi dekorasi 6 meter, fresh flower, mini garden depan dekor, white flooring, cutting 3D, lighting dekorasi, kursi pengantin 1 set, welcome gate, dekorasi photobooth, lorong jalan, kursi tafani 1 set, kotak angpao 1, dan fresh hand bouquet. Sedangkan, untuk opsi kedua dari paket wedding senilai Rp. 18.000.000 ini meliputi paket make up, 
dokumentasi, dan dekorasi. Paket make up ini meliputi make up with retouch, 3 pasang baju pengantin, melati segar, henna dan fake nail, softlens, eyelash premium, aksesoris adat (Sunda Siger atau Solo Putri), make up sepasang orang tua dan besan serta kostum, make up pembawa kembar mayang beserta kostum, alat temu atau pemandu temu, dan bunga setaman. Untuk dokumentasi meliputi magazine 20x30 20 pages, video sinematik 1 dan 3 menit, 1 kali cetak 16Rs, soft file edit back up serta flashdisc, dan untuk dekorasi meliputi dekorasi pelaminan, taman dekorasi, dekorasi lorong, welcome gate, karpet jalan, photo corner, dan fresh hand bouquet."

Untuk lebih lanjut, Ibu Khusnul juga menambahkan berbagai ketentuan yang berkaitan dengan paket wedding di Salon Ima, sebagai berikut.

"Paket wedding senilai Rp. 18.000 .000 ini memiliki ketentuan yang harus diketahui dan dipahami oleh customer. Ketentuan tersebut meliputi biaya senilai Rp.18.000.000 ini belum termasuk panggung, tenda, dan slayer. Untuk durasi sewa dekor berlaku selama 1x24 jam. Sedangkan, untuk durasi akad, temu, resepsi di hari yang sama terhitung 8 jam kerja dimulai dari make up. Tambahan di luar paket akan dikenakan biaya dan untuk lock tanggal pernikahan, customer harus melakukan DP minimal Rp. 1.000.000. Selain itu, customer hanya dapat melakukan 2 kali perubahan sejak mengisi form wedding."

Dari pernyataan di atas, maka dapat disimpulkan bahwa harga jual paket wedding di Salon Ima Skincare \& Make Up Desa Kenongo Kecamatan Wlingi Kabupaten Blitar memiliki harga jual yang berbeda untuk setiap paketnya. Berikut ini daftar paket wedding yang ada di Salon Ima Skincare \& Make Up.

Tabel 6 Data Harga Jual Paket Wedding

\begin{tabular}{|c|c|}
\hline Jenis Biaya & Total Biaya (Rp) \\
\hline OPSI 1 & \multirow[t]{14}{*}{ Rp. 18.000 .000} \\
\hline Make Up & \\
\hline Make up with retouch & \\
\hline 3 pasang baju pengantin & \\
\hline Melati segar & \\
\hline Henna dan fake nail & \\
\hline Softlens & \\
\hline Eyelash premium & \\
\hline Aksesoris adat (Sunda Siger atau Solo Putri) & \\
\hline $\begin{array}{l}\text { Make up sepasang orang tua dan besan beserta } \\
\text { kostum }\end{array}$ & \\
\hline Make up pembawa kembar mayang beserta kostum & \\
\hline Alat temu atau pemandu temu & \\
\hline Bunga setaman & \\
\hline MC jawa & \\
\hline
\end{tabular}




\begin{tabular}{|l|} 
Dokumentasi \\
\hline Unlimited shoot \\
\hline Album magazine 20 pages \\
\hline Teaser 1 minutes \\
\hline Sinematik 3 minutes \\
\hline 2 photographer \\
\hline 1 videographer \\
\hline 1 assisten \\
\hline Soft file back up \\
\hline Flashdisc \\
\hline Dekorasi \\
\hline Dekorasi 6 meter \\
\hline Fresh flower \\
\hline Mini garden depan dekor \\
\hline White flooring \\
\hline Cutting 2 D \\
\hline Lighting dekorasi \\
\hline Kursi pengantin 1 set \\
\hline Welcome gate \\
\hline Dekorasi photobooth \\
\hline Lorong jalan \\
\hline Kursi tifani 1 set \\
\hline Kotak angpao 1 \\
\hline Fresh hand bouquet \\
\hline
\end{tabular}

Sumber : Data Diolah, 2021.

Berdasarkan Tabel 6 di atas menunjukkan data dari harga jual paket wedding opsi 1 yang ada di Salon Ima Skincare \& Make Up. Dari tabel di atas dapat diketahui bahwa paket wedding opsi 1 yang berisi paket make up, paket dokumentasi dan dekorasi dipatok dengan harga Rp. 18.000.000,-. Include dari masing-masing paket meliputi make up, dokumentasi, dan dekorasi.

Tabel 7 Data Harga Jual Paket Wedding

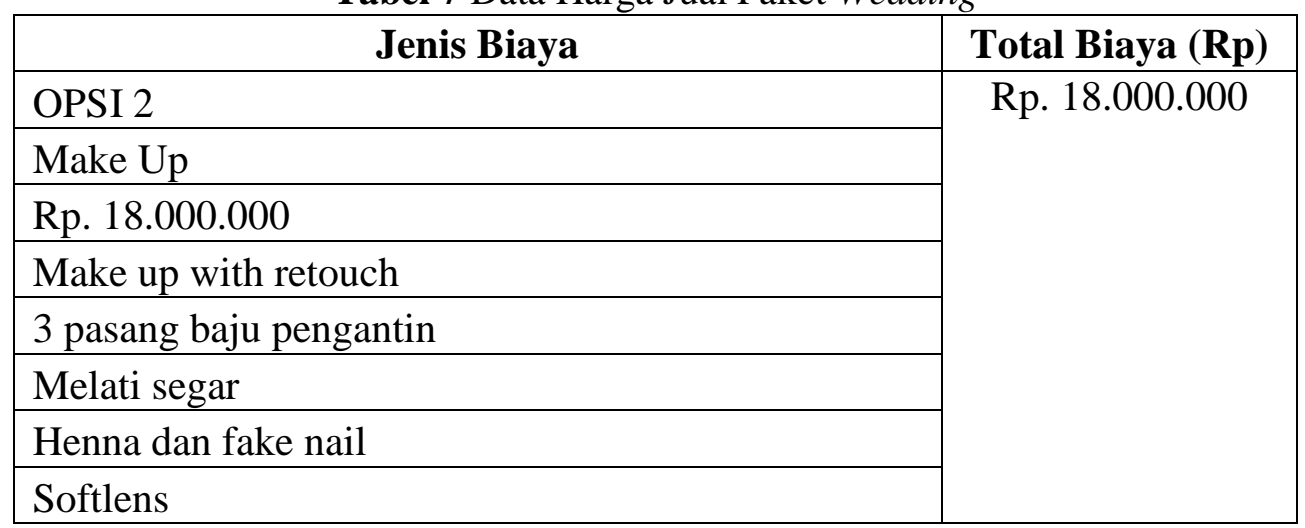




\begin{tabular}{|l|} 
Eyelash premium \\
\hline Aksesoris adat (Sunda Siger atau Solo Putri) \\
\hline $\begin{array}{l}\text { Make up sepasang orang tua dan besan beserta } \\
\text { kostum }\end{array}$ \\
\hline Make up pembawa kembar mayang beserta kostum \\
\hline Alat temu atau pemandu temu \\
\hline Bunga setaman \\
\hline Dokumentasi \\
\hline Magazine 20x30 20 pages \\
\hline Video sinematik 1 dan 3 menit \\
\hline 1 kali cetak 16Rs \\
\hline Soft file edit back up \\
\hline Flashdisc \\
\hline Dekorasi \\
\hline Dekorasi pelaminan \\
\hline Taman dekorasi \\
\hline Dekorasi lorong \\
\hline Welcome gate \\
\hline Karpet jalan \\
\hline Photo corner \\
\hline Fresh hand bouquet \\
\hline
\end{tabular}

Sumber : Data Diolah, 2021.

Berdasarkan Tabel 7 di atas menunjukkan data dari harga jual paket wedding opsi 2 yang ada di Salon Ima Skincare \& Make Up. Dari tabel di atas dapat diketahui bahwa paket wedding opsi 2 yang berisi paket make up, paket dokumentasi dan dekorasi dipatok dengan harga Rp. 18.000.000,-. Include dari paket make up meliputi make up with retouch, 3 pasang baju pengantin, melati segar, henna dan fake nail, softlens, eyelash premium, aksesoris adat (Sunda Siger atau Solo Putri), make up sepasang orang tua dan besan beserta kostum, make up pembawa kembar mayang beserta kostum, alat temu atau pemandu temu, dan bunga setaman. Untuk paket dokumentasi berisikan magazine 20x30 20 pages, video sinematik 1 dan 3 menit, 1 kali cetak 16Rs, soft file edit back up, serta flashdisc, dan untuk paket dekorasi meliputi dekorasi pelaminan, taman dekorasi, dekorasi lorong, welcome gate, karpet jalan, photo corner, dan fresh hand bouquet.

Selain, adanya paket wedding seharga Rp. 18.000 .000 seperti yang dipaparkan di atas, Salon Ima Skincare \& Make Up juga memiliki bundling package wedding dengan harga jual sebesar Rp. 16.000.000,-. Paket wedding ini meliputi paket make up, paket dokumentasi, dan paket dekorasi. Hal ini sesuai dengan kutipan wawancara dengan Ibu Khusnul Khotimah selaku pemilik usaha Salon Ima Skincare \& Make Up yang disajikan sebagai berikut :

"Selain adanya paket wedding seharga Rp.18.000.000,-, di sini juga ada bundling package wedding seharga Rp. 16.000.000,-. Paket wedding ini meliputi paket make up, paket dokumentasi dan paket dekorasi. Include dari paket make up di sini meliputi make up with retouch, 3 pasang baju pengantin, 
melati segar, henna dan fake nail, softlens, eyelash premium, aksesoris adat (Sunda Siger atau Solo Putri), make up sepasang orang tua dan besan beserta kostum, make up pembawa kembar mayang beserta kostum, alat temu atau pemandu temu, dan bunga setaman. Untuk paket dokumentasi di sini meliputi magazine 20x30 20 halaman, video sinematik 1 dan 3 menit, 1 kali cetak 16Rs, soft file edit back up, serta flashdisc, dan untuk paket dekorasi yang ada untuk jenis paket ini meliputi dekorasi 6 meter, fresh flower, mini garden depan dekor, white flooring, cutting 3D, lighting dekorasi, kursi pengantin 1 set, welcome gate, dekorasi photobooth, lorong jalan, kursi tifani 1 set, kotak angpao 1, dan fresh hand bouquet."

Untuk lebih lanjut, Ibu Khusnul juga menambahkan berbagai ketentuan yang berkaitan dengan paket wedding di Salon Ima, sebagai berikut.

"Paket wedding senilai Rp. 16.000.000 ini memiliki ketentuan yang harus diketahui dan dipahami oleh customer. Ketentuan tersebut meliputi biaya senilai Rp. 16.000.000 ini sudah termasuk free MC Jawa, belum termasuk panggung, tenda, dan slayer. Untuk durasi sewa dekor berlaku selama 1x24 jam. Sedangkan, untuk durasi akad, temu, resepsi di hari yang sama terhitung 8 jam kerja dimulai dari make up. Tambahan atau adanya request dari customer di luar paket wedding akan dikenakan biaya tambahan, misalnya adanya tambahan biaya bagi customer non hijab dan untuk lock tanggal pernikahan, customer harus melakukan DP minimal Rp. 1.000.000. Selain itu, customer hanya dapat melakukan 2 kali perubahan sejak mengisi form wedding."

Dari pernyataan di atas, maka dapat disimpulkan bahwa harga jual paket wedding di Salon Ima Skincare \& Make Up Desa Kenongo Kecamatan Wlingi Kabupaten Blitar memiliki harga jual yang berbeda untuk setiap paketnya. Berikut ini daftar paket wedding yang ada di Salon Ima Skincare \& Make Up.

Tabel 8 Data Harga Jual Paket Wedding

\begin{tabular}{|c|c|}
\hline Jenis Biaya & Total Biaya (Rp) \\
\hline Make Up & \multirow{13}{*}{ Rp. 16.000 .000} \\
\hline Make up with retouch & \\
\hline 3 pasang baju pengantin & \\
\hline Melati segar & \\
\hline Henna dan fake nail & \\
\hline Softlens & \\
\hline Eyelash premium & \\
\hline Aksesoris adat (Sunda Siger atau Solo Putri) & \\
\hline $\begin{array}{l}\text { Make up sepasang orang tua dan besan beserta } \\
\text { kostum }\end{array}$ & \\
\hline Make up pembawa kembar mayang beserta kostum & \\
\hline Alat temu atau pemandu temu & \\
\hline Bunga setaman & \\
\hline Dokumentasi & \\
\hline
\end{tabular}




\begin{tabular}{|l|} 
Magazine 20x30 20 halaman \\
\hline Video sinematik 1 dan 3 menit \\
\hline 1 kali cetak 16Rs \\
\hline Soft file edit back up \\
\hline Flashdisc \\
\hline Dekorasi \\
\hline Dekorasi 6 meter \\
\hline Fresh flower \\
\hline Mini garden depan dekor \\
\hline White flooring \\
\hline Cutting 3D \\
\hline Lighting dekorasi \\
\hline Kursi pengantin 1 set \\
\hline Welcome gate \\
\hline Dekorasi photobooth \\
\hline Lorong jalan \\
\hline Kursi tifani 1 set \\
\hline Kotak angpao 1 \\
\hline Fresh hand bouquet \\
\hline
\end{tabular}

Sumber : Data Diolah, 2021.

Berdasarkan Tabel 8 di atas menunjukkan data dari harga jual paket wedding yang ada di Salon Ima Skincare \& Make Up. Dari tabel di atas dapat diketahui bahwa paket wedding di sana meliputi paket make up, paket dokumentasi dan dekorasi yang dipatok dengan harga Rp. 16.000.000,-. Include dari paket make up meliputi make up with retouch, 3 pasang baju pengantin, melati segar, henna dan fake nail, softlens, eyelash premium, aksesoris adat (Sunda Siger atau Solo Putri), make up sepasang orang tua dan besan beserta kostum, make up pembawa kembar mayang beserta kostum, alat temu atau pemandu temu, dan bunga setaman. Untuk paket dokumentasi berisikan magazine 20x30 20 halaman, video sinematik 1 dan 3 menit, 1 kali cetak 16Rs, soft file edit back up, serta flashdisc, dan untuk paket dekorasi meliputi dekorasi 6 meter, fresh flower, mini garden depan dekor, white flooring, cutting 3D, lighting dekorasi, kursi pengantin 1 set, welcome gate, dekorasi photobooth, lorong jalan, kursi tifani 1 set, kotak angpao 1, dan fresh hand bouquet.

\section{Penentuan Harga Jual Jasa Pada Salon Ima Skincare \& Make Up dengan Menggunakan Metode Cost Plus Pricing}

Harga jual merupakan sejumlah biaya yang dikeluarkan oleh suatu perusahaan di mana perusahaan tersebut telah memproduksi barang maupun jasa dengan selalu menambah presentase laba yang perusahaan inginkan. Oleh karena itu, untuk mencapai laba yang diinginkan salah satu cara yang dapat dilakukan untuk menarik minat konsumen ialah dengan cara menentukan harga yang tepat untuk setiap barang maupun jasa yang dikeluarkan. Maksud dari harga yang tepat ialah harga yang sesuai dengan kualitas produk suatu barang atau jasa, dan harga tersebut bisa memberikan kepuasan kepada konsumen. 
Cost plus pricing merupakan suatu metode dari penetapan harga jual di mana penetapan harga ini ditentukan dengan menambahkan biaya total produksi dengan nilai margin. Berikut perhitungan harga paket akad dan wedding di Salon Ima Skincare \& Make Up melalui model penetapan harga jual cost plus pricing dengan laba yang diinginkan sebesar $20 \%$, maka :

\section{Harga Jual Paket Akad di Salon Ima Skincare \& Make Up}

a. Harga Jual Jasa Make Up Akad

Harga Jual $=$ Total biaya + margin

$=$ Rp. $1.500 .000+(20 \%$ x Rp. 1.500 .000$)$

$=$ Rp. $1.500 .000+$ Rp. 300.000

$=$ Rp. 1.800.000,-

Jadi, harga jual jasa make up akad setelah menambahkan laba 20\% adalah Rp.

$1.800 .000,-$.

b. Harga Jual Jasa Paket Akad 1

Harga Jual $=$ Total biaya + margin

= Rp. $2.200 .000+(20 \%$ x Rp. 2.200.000)

$=$ Rp. $2.200 .000+$ Rp. 440.000

$=$ Rp. 2.640.000,-

Jadi, harga jual jasa make up akad setelah menambahkan laba 20\% adalah Rp.

2.640.000,-.

\section{c. Harga Jual Jasa Paket Akad 2}

Harga Jual $=$ Total biaya + margin

$=$ Rp. $3.500 .000+(20 \% \times$ Rp. 3.500 .000$)$

$=$ Rp. $3.500 .000+$ Rp. 700.000

$=$ Rp. 4.200.000,-

Jadi, harga jual jasa make up akad setelah menambahkan laba $20 \%$ adalah Rp.

4.200.000,-.

\section{d. Harga Jual Jasa Paket Akad 3}

Harga Jual $=$ Total biaya + margin

$=$ Rp. $5.500 .000+(20 \%$ x Rp. 5.500.000)

$=$ Rp. $5.500 .000+$ Rp. 1.100 .000

$=$ Rp. 6.600.000,-

Jadi, harga jual jasa make up akad setelah menambahkan laba $20 \%$ adalah Rp.

6.600.000,--.

Berdasarkan perhitungan dari penentuan harga jual jasa paket akad di Salon Ima Skincare \& Make Up dengan metode cost plus pricing seperti perhitungan yang ada di atas, dapat diperoleh data sebagai berikut.

Tabel 9 Data Harga Jual Jasa Paket Akad dengan Metode Cost Plus Pricing

\begin{tabular}{|l|l|}
\hline Jenis Paket Akad & Harga Jual (Rp) \\
\hline Make up akad & 1.800 .000 \\
\hline Paket akad 1 & 2.640 .000 \\
\hline Paket akad 2 & 4.200 .000 \\
\hline Paket akad 3 & 6.600 .000 \\
\hline
\end{tabular}

Sumber : Data Diolah, 2021. 
Berdasarkan Tabel 9 di atas menunjukkan data dari harga jual jasa paket akad dengan menggunakan metode cost plus pricing pada Salon Ima Skincare \& Make Up. Tabel di atas menunjukkan harga jual dari berbagai jenis paket akad yang ada di Salon Ima mulai jadi paket make up akad, paket akad 1, paket akad 2, dan paket akad 3. Setelah dilakukan perhitungan harga jual jasa dari paket akad yang ada di Salon Ima dengan menggunakan metode cost plus pricing ditemukan harga jual dari masing-masing paket yang ada. Harga jual yang dimaksud yaitu harga jual dari paket make up akad sebesar Rp. 1.800.000,-, harga jual paket akad 1 sebesar Rp. 2.640.000,-, harga jual paket akad 2 sebesar Rp. 4.200.000,-, dan harga jual paket akad 3 sebesar Rp. 6.600.000,-.

\section{Harga Jual Bundling Package Wedding di Salon Ima Skincare \& Make Up}

a. Harga Jual Paket Wedding 1

Harga Jual $=$ Total biaya + margin

$=$ Rp. $18.000 .000+(20 \% \times$ Rp. 18.000 .000$)$

$=$ Rp. $18.000 .000+$ Rp. 3.600 .000

$=$ Rp. 21.600.000,-

Jadi, harga jual jasa make up akad setelah menambahkan laba $20 \%$ adalah Rp.

21.600.000,--.

\section{b. Harga Jual Paket Wedding 2}

Harga Jual $=$ Total biaya + margin

$=$ Rp. $16.000 .000+(20 \% \times$ Rp. 16.000 .000$)$

$=$ Rp. $16.000 .000+$ Rp. 3.200 .000

$=$ Rp. 19.200.000,-

Jadi, harga jual jasa make up akad setelah menambahkan laba $20 \%$ adalah Rp.

19.200.000,-.

Berdasarkan perhitungan harga jual jasa paket wedding yang ada di Salon Ima Skincare \& Make Up dengan metode cost plus pricing seperti yang ada di atas, dapat dipahami sebagai berikut.

Tabel 10 Data Harga Jual Jasa Paket Wedding dengan Metode Cost Plus Pricing

Jenis Paket Wedding

Paket wedding 1

Paket wedding 2

Sumber : Data Diolah, 2021.

Berdasarkan Tabel 10 di atas menunjukkan data dari harga jual jasa paket wedding dengan menggunakan metode cost plus pricing pada Salon Ima Skincare \& Make Up. Tabel di atas menunjukkan harga jual dari berbagai jenis paket wedding yang ada di Salon Ima mulai jadi paket wedding 1 dan paket wedding 2. Setelah dilakukan perhitungan harga jual jasa dari paket wedding yang ada di Salon Ima dengan menggunakan metode cost plus pricing ditemukan harga jual dari masingmasing paket yang ada. Harga jual yang dimaksud yaitu harga jual dari paket wedding 1 sebesar Rp. 21.600.000,-, dan harga jual paket wedding 2 sebesar Rp. 19.200.000,--

\section{Perbandingan Penentuan Harga Jual Jasa Pada Salon Ima Skincare \& Make Up dengan Menggunakan Metode Cost Plus Pricing}


Perbandingan penentuan harga jual merupakan gambaran mengenai selisih dari masing-masing harga jual yang ditentukan. Terdapat perbandingan harga jual jasa dari paket akad dan paket wedding pada Salon Ima Skincare \& Make Up dari yang penentuan harga jualnya berdasarkan harga pasaran dibandingkan dengan penentuan harga jual dengan menggunakan metode cost plus pricing. Perbandingan penentuan harga tersebut dapat dilihat pada tabel di bawah ini :

1. Perbandingan Harga Jual Paket Akad di Salon Ima Skincare \& Make Up

Tabel 11 Perbandingan Harga Jual Paket Akad di Salon Ima Skincare \& Make Up

\begin{tabular}{|l|l|l|l|}
\hline \multicolumn{1}{|c|}{$\begin{array}{c}\text { Jenis Paket } \\
\text { Akad }\end{array}$} & $\begin{array}{c}\text { Harga Jual } \\
\text { Pasaran (Rp) }\end{array}$ & $\begin{array}{c}\text { Harga Jual Cost } \\
\text { Plus Pricing } \\
\text { (Rp) }\end{array}$ & \multicolumn{1}{|c|}{ Selisih (Rp) } \\
\hline Make up akad & 1.500 .000 & 1.800 .000 & 300.000 \\
\hline Paket akad 1 & 2.200 .000 & 2.640 .000 & 440.000 \\
\hline Paket akad 2 & 3.500 .000 & 4.200 .000 & 700.000 \\
\hline Paket akad 3 & 5.500 .000 & 6.600 .000 & 1.100 .000 \\
\hline
\end{tabular}

Sumber : Data Diolah, 2021.

Berdasarkan Tabel 11 di atas menunjukan perbandingan harga jual paket akad yang ada di Salon Ima Skincare \& Make Up. Pada tabel tersebut dapat dilihat perbedaan harga jual paket akad yang ditetapkan berdasarkan harga pasaran dari berbagai usaha sejenis dengan harga jual paket akad berdasarkan metode cost plus pricing. Menurut tabel perbandingan tersebut penggunaan metode cost plus pricing pada harga jual paket akad menjadi lebih mahal dan menghasilkan laba. Pada tabel itu dapat diketahui bahwa dari berbagai jenis paket akad semuanya menghasilkan laba. Jenis paket akad yang ada di sana dapat dibagi menjadi 4 (empat) jenis, yaitu paket make up akad, paket akad 1, paket akad 2, dan paket akad 3. Selisih dari paket make up akad antara harga jual pasaran dengan harga jual cost plus pricing yaitu Rp. 300.000 yang mana harga jual pasaranya Rp. 1.500.000 dibandingkan dengan harga jual dengan metode cost plus pricing sebesar Rp. 1.800 .000 yang berasal dari $20 \%$ laba yang diinginkan. Untuk paket akad 1, dapat diketahui perbandingan antara harga jual pasaran dari Rp. 2.200.000 dengan harga jual cost plus pricing sebesar Rp. 2.640.000 dari 20\% laba yang diinginkan menghasilkan selisih sebesar Rp. 440.000. Lain halnya dengan harga jual dari paket akad 2. Selisih dari paket akad 2 antara harga jual pasaran dengan harga jual cost plus pricing yaitu Rp. 700.000 yang mana harga jual pasarannya Rp. 3.500.000 dibandingkan dengan harga jual cost plus pricing sebesar Rp.4.200.000 yang berasal dari 20\% laba yang diinginkan. Sedangkan, untuk paket akad 3 pada tabel di atas dapat diketahui dari harga jual pasaran yang telah ditentukan sebesar Rp. 5.500.000 apabila dibandingkan dengan penentuan harga jual paket akad 3 dengan metode cost plus pricing mendapatkan harga jual sebesar Rp. 6.600.000 yang berasal dari 20\% laba yang diinginkan. Ketika harga jual tersebut dibandingkan, maka menghasilkan selisih yang cukup besar dari penentuan harga jual paket akad 3 sebesar Rp. 1.100.000,-.

\section{Perbandingan Harga Jual Bundling Package Wedding di Salon Ima Skincare \& Make Up}

Tabel 12 Perbandingan Harga Jual Paket Wedding di Salon Ima Skincare \& Make Up 


\begin{tabular}{|c|l|l|l|}
\hline $\begin{array}{c}\text { Jenis Paket } \\
\text { Wedding }\end{array}$ & \multicolumn{1}{|c|}{$\begin{array}{c}\text { Harga Jual } \\
\text { Pasaran (Rp) }\end{array}$} & $\begin{array}{c}\text { Harga Jual } \\
\text { Cost Plus } \\
\text { Pricing (Rp) }\end{array}$ & Selisih (Rp) \\
\hline Paket wedding 1 & 18.000 .000 & 21.600 .000 & 3.600 .000 \\
\hline Paket wedding 2 & 16.000 .000 & 19.200 .000 & 3.200 .000 \\
\hline
\end{tabular}

Sumber : Data Diolah, 2021.

Berdasarkan Tabel 12 di atas menunjukkan perbandingan harga jual paket wedding di Salon Ima Skincare \& Make Up menurut penentuan harga jual pasaran dengan penentuan harga jual yang menggunakan metode cost plus pricing. Dari tabel tersebut menunjukkan bahwa perbandingan harga jual jasa wedding pada usaha Salon Ima Ima Skincare \& Make Up dengan metode cost plus pricing mengalami perbedaan. Perbedaan tersebut dapat dilihat dari harga jual yang dihasilkan ketika penentuannya menggunakan metode cost plus pricing. Hal ini dapat dilihat dari berbagai jenis paket wedding yang disediakan. Jenis paket wedding di sana ada paket wedding 1 dan paket wedding 2 . Pada paket wedding 1 dapat diketahui harga jual pasarannya sebesar Rp. 18.000.000. Apabila harga jual pasaran ini dibandingkan dengan harga jual cost plus pricing sebesar Rp. 21.600 .000 yang berasal dari $20 \%$ laba yang diinginkan menghasilkan selisih sebesar Rp. 3.600.000. Lain halnya dengan paket wedding 2. Selisih dari paket wedding 2 ini sebesar Rp. 3.200 .000 yang mana berasal dari perbandingan antara harga jual pasaran sebesar Rp. 16.000.000 dibandingkan dengan harga jual cost plus pricing sebesar Rp. 19.200.000 yang berasal dari $20 \%$ laba yang diinginkan.

\section{KESIMPULAN}

Berdasarkan penelitian ini dapat disimpulkan, bahwa :

1. Penentuan harga jual jasa make up dan hair do yang ada di Salon Ima Skincare \& Make Up masih ditentukan dengan mengacu pada harga pasaran yang dilihat dari penentuan harga jual sesuai dengan usaha yang sejenis, tanpa mempertimbangkan laba yang inginkan.

2. Salon Ima Skincare \& Make Up memiliki berbagai jasa yang ditawarkan seperti paket akad dan paket wedding. Paket akad di sana meliputi paket make up akad, paket akad 1, paket akad 2, dan paket akad 3. Sedangkan, untuk paket wedding meliputi paket wedding 1 dan paket wedding 2. Harga jual jasa dari masing-masing paket yang ada masih ditentukan berdasarkan harga pasaran. Artinya, harga jual jasa masih ditentukan dengan memperhatikan harga jual jasa dari usaha yang sejenis. Hal ini tentu belum diperhitungkan keinginan dari laba yang dicapai. Masing-masing harga jual jasa dari paket akad dan paket wedding yang dimulai dari paket akad yaitu paket make up akad sebesar Rp. 1.500.000, dan untuk paket akad 1, paket akad 2, dan paket akad 3 masing-masing paket itu dipatok dengan harga Rp. 2.200.000, Rp. 3.500.000, dan Rp. 5.500.000. Sedangkan, untuk paket wedding mulai dari paket wedding 1 dan paket wedding 2 dipatok dengan harga Rp. 18.000.000 dan Rp. 16.000.000. 
3. Ketika harga jual jasa dari Salon Ima Skincare \& Make Up ditentukan dengan menggunakan metode cost plus pricing menunjukkan perbedaan harga jual yang cukup jelas. Dengan menggunakan metode penentuan harga jual tersebut, pemilik dapat menentukan laba yang diinginkan sebesar $20 \%$ dari setiap paket jasa yang tersedia. Dari penentuan harga jual jasa dengan menggunakan metode cost plus pricing, usaha paket akad dari pemilik usaha mengalami kenaikan harga mulai dari paket make up akad sebesar Rp. 300.000. Kenaikan tersebut membuat harga jual jasa make up akad berubah menjadi Rp. 1.800.000. Untuk paket akad 1 dengan harga jual cost plus pricing sebesar Rp. 2.640 .000 dari 20\% laba yang diinginkan menghasilkan selisih sebesar Rp. 440.000 dari harga jual pasaran. Lain halnya dengan harga jual dari paket akad 2. Selisih dari paket akad 2 antara harga jual pasaran dengan harga jual cost plus pricing yaitu Rp. 700.000 yang mana menghasilkan harga jual cost plus pricing sebesar Rp.4.200.000. Sedangkan, penentuan harga jual paket akad 3 dengan metode cost plus pricing mendapatkan harga jual sebesar Rp. 6.600 .000 dengan selisih Rp. 1.100.000 dari harga jual pasaran. Selanjutnya, untuk paket wedding mulai dari paket wedding 1 dan paket wedding 2 juga mengalami perubahan harga jual. Pada paket wedding 1 harga jual cost plus pricing sebesar Rp. 21.600 .000 dengan selisih sebesar Rp. 3.600.000 dari harga pasaran. Lain halnya dengan paket wedding 2 menghasilkan selisih harga sebesar Rp. 3.200.000 dari harga pasaran yang menghasilkan harga jual cost plus pricing sebesar Rp. 19.200.000.

\section{DAFTAR PUSTAKA}

Alma, Buchari. 2014. Manajemen Pemasaran dan Pemasaran Jasa. Yogyakarta: Alfabeta.

Anggareni, Aji Desilia. 2019. Analisis Penentuan Harga Jual Cermin Alumunium Dengan Menggunakan Metode Cost Plus Pricing Pada Toko Kaca Mulia Berkah Di Tenggarong. JEMI, Vol. 19, No. 2, Desember 2019.

Hartanti, Rina. 2020. Apakah Cost Plus Pricing Masih Relevan Di Masa Covid-19. Jurnal Ekonomi, Volume XXV, No. 03 November 2020.

James M. Reeve. 2013. Pengantar Akuntansi Adaptasi Indonesia. Jakarta: Salemba Empat. Kotler, Philip., dan Keller,

Lane Kevin. 2012. Marketing Management, Edisi 14. Global Edition. Pearson Prentice Hall. . 2018. Manajemen Pemasaran, Edisi 12, Jilid 2, Indeks.

Krismiaji dan Aryani A. Y. 2011. Akuntansi Manajemen, Edisi 2. Yogyakarta: Unit Penerbit dan Percetakan Sekolah Tinggi Ilmu Manajemen YKPN.

Kusumamurti, Maria Di Livia. 2019. Perancangan Publikasi Jasa Make Up Artist dan Hairdo Di Livia. Tugas Akhir. Institut Seni Indonesia Yogyakarta.

Mulyadi. 2012. Akuntansi Biaya, Edisi 5. Yogyakarta: UPP-STIM YKPN, Graha Ilmu.

. 2016. Akuntansi Biaya, Edisi 5. Yogyakarta: UPP STIM YKPN.

Mursyidi. 2010. Akuntansi Biaya (Conventional Costing, Just in Time dan Activity Based Costing), Cetakan ke-2. Bandung: Refika Aditama. 
Ningtyas N, Meydita Nur Ayu. 2019. Analisa Penetapan Harga Jual Jasa Make Up Artist (MUA) Di Surabaya (Studi Kasus Pada Ristya Stefanie Make Up \& Wedding Design). Skripsi. Sekolah Tinggi Ilmu Ekonomi Mahardika.

Purnama, D. 2017. Perhitungan Harga Pokok Produksi dalam Menentukan Harga Jual melalui Metode Cost Plus Pricing dengan Pendekatan Full Costing (Studi Kasus PT.Prima Istiqamah Sejahtera Di Makassar). Skripsi. UIN Alauddin Makassar.

Puspa, Camerina. 2013. Broadcast Make-Up. Jakarta: Gramedia Pustaka Utama.

Rahmadhani, Ari Putri dan Kamayanti, Ari. 2016. Etika Penentuan Harga Pada Perusahaan Jasa (Studi Kasus Pada Salon Kecantikan Di Kabupaten Ponorogo Jawa Timur). Jurnal Ilmiah Mahasiswa FEB - JIMFEB, Vol. 4, No. 1, 2016.

Sodikin, S.S. 2015. Akuntansi Managemen Sebuah Pengantar. Yogyakarta: UPP STIM YKPN.

Sriyadi, 2010. Bisnis Pengantar Ilmu Perusahaan Modern. Jakarta: Raja Grafindo Persada.

Sugiyono. 2016. Metode Penelitian Kuantitatif, Kualitatif, dan R\&D. Bandung: Alfabeta.

Sujarweni, Wiratna.V. 2016. Akuntansi Manajemen: Teori dan Aplikasi. Yogyakarta: Pustaka Baru Press.

Supriyono R.A. 2011. Akuntansi Biaya: Pengumpulan Biaya dan Penentuan Harga Pokok, Edisi Kedua, Cetakan Kelima Belas. Yogyakarta: BPFE.

Suwardjono. 2015. Teori Akuntansi Perekayasaan Pelaporan Keuangan. Yogyakarta: BPFE.

Swastha, Basu. 2010. Manajemen Penjualan, Edisi 3. Yogyakarta: BPFE.

Thomas, Sumarsan. 2013. Perpajakan Indonesia. Jakarta: Indeks.

Tjiptono, Fandy. 2015. Strategi Pemasaran, Edisi Ke-3. Yogyakarta: Andi.

Walter, dkk. 2012. Akuntansi Keuangan. Jakarta: Erlangga.

Woran, Reza., Ilat, Ventje., dan Lidia Mawikere. 2014. Penentuan Harga Jual Produk Dengan Menggunakan Metode Cost Plus Pricing Pada UD. Vanela. Jurnal EMBA, Vol. 2, No. 2, Juni 2014. 